\title{
Levodopa versus non-levodopa brain language fMRI in Parkinson's disease
}

\author{
RMf de linguagem na doença de Parkinson: levodopa versus não levodopa \\ Paula Ricci Arantes ${ }^{1}$, Heloise Helena Gobato ${ }^{2}$, Bárbara Bordegatto Davoglio ${ }^{2}$, \\ Maria Ângela Maramaldo Barreiros ${ }^{3}$, André Carvalho Felício ${ }^{3}$, Orlando Graziani Povoas Barsottini ${ }^{4}$, \\ Luiz Augusto Franco de Andrade ${ }^{3}$, Edson Amaro Junior ${ }^{5}$
}

\begin{abstract}
Objective: To identify the effect of levodopa in language areas in Parkinson's disease patients. Methods: We evaluated 50 patients with mild to moderate Parkinson's disease, age and gender paired to 47 healthy volunteers. We selected two homogeneous groups of 18 patients taking levodopa and 7 no levodopa patients. The functional magnetic resonance imaging verbal fluency task, with low and high cognitive demands, was performed at a 3T magnetic resonance imaging equipment. Data was analyzed with XBAM software for group maps and ANOVA comparison. Results: Patients without levodopa had more activation than the ones with levodopa in the medial frontal and in the left frontal and parieto-occipital areas. The striatal activation in patients taking levodopa had similar result of the activation detected in the healthy volunteer group. Parietooccipital areas were less activated in the levodopa group than in the no levodopa one. Conclusion: Parkinson's disease patients without levodopa replacement, during a verbal fluency effort, had more diffuse and intense cerebral activation in left hemisphere, mainly in the frontal and parieto-occipital areas. The striatal activation in verbal fluency of patients with levodopa intake was more similar to the activation found in healthy volunteers. These initial evidences suggested a role of levodopa inhibiting activation in parieto-occipital compensating areas.
\end{abstract}

Keywords: Parkinson disease; Language; Levodopa; Functional magnetic resonance imaging; Verbal fluency

\section{RESUMO}

Objetivo: Identificar o efeito da levodopa nas áreas de linguagem em pacientes com doença de Parkinson. Métodos: Foram avaliados 50 pacientes com doença de Parkinson leve a moderada e pareados, por gênero e idade, a 47 voluntários saudáveis. Foram selecionados dois grupos homogêneos de 18 pacientes que usavam e 7 que não usavam levodopa. 0 exame de ressonância magnética funcional, com tarefa de fluência verbal por geração de palavras de maiores e menores demandas cognitivas, foi realizado em equipamento de 3T. Os dados foram analisados pelo programa XBAM para os mapas de grupo e as comparações ANOVA. Resultados: Os pacientes sem utilização de levodopa tiveram maior ativação nas áreas frontais mediais e esquerdas e áreas parieto-occipitais que com levodopa. A ativação estriatal nos pacientes em uso de levodopa foi similar à detectada no grupo de voluntários saudáveis. Conclusão: Pacientes com doença de Parkinson, sem utilização de levodopa durante 0 esforço da fluência verbal, tiveram ativação mais difusa e intensa, principalmente no hemisfério esquerdo, em áreas frontais e parieto-occipitais. A atividade cerebral estriatal na fluência verbal de pacientes em uso de levodopa foi semelhante a dos voluntários saudáveis. Essas evidências iniciais sugerem um papel inibidor da levodopa na ativação compensatória de áreas parieto-occipitais.

Descritores: Doença de Parkinson; Linguagem; Levodopa; Ressonância magnética funcional; Fluência verbal

\section{INTRODUCTION}

Parkinson's Disease (PD) is a common adultneurodegenerative condition, characterized by dopaminergic neuronal loss within the substantia nigra particularly in the ventral component of the pars $\operatorname{compacta}^{(1)}$.

\footnotetext{
Study carried out at Hospital Israelita Albert Einstein - HIAE, São Paulo (SP), Brazil.

1 Instituto do Cérebro - InCe, Hospital Israelita Albert Einstein - HIAE, São Paulo (SP), Brazil; Faculdade de Medicina da Universidade de São Paulo - USP, São Paulo (SP), Brazil.

${ }^{2}$ Instituto do Cérebro - InCe, Hospital Israelita Albert Einstein - HIAE, São Paulo (SP), Brazil; Faculdade de Enfermagem do Hospital Israelita Albert Einstein - HIAE - São Paulo (SP), Brazil.

${ }^{3}$ Instituto do Cérebro - InCe, Hospital Israelita Albert Einstein - HIAE, São Paulo (SP), Brazil.

${ }^{4}$ Instituto do Cérebro - InCe, Hospital Israelita Albert Einstein - HIAE, São Paulo (SP), Brazil; Department of Neurology and Neurosurgery, Universidade Federal de São Paulo - UNIFESP, São Paulo (SP), Brazil.

${ }^{5}$ Department of Diagnostic Imaging and Instituto do Cérebro - InCe, Hospital Israelita Albert Einstein - HIAE, São Paulo (SP), Brazil.

Corresponding author: Paula Ricci Arantes - Instituto do Cérebro - InCe, Hospital Israelita Albert Einstein - Avenida Albert Einstein 627/701 - Morumbi - Zip code: 05651-901 São Paulo (SP), Brasil -

Phone: (55 11) 3865-6791 - E-mail: parantes@usp.br
}

Received on: Mar 19, 2012 - Accepted on: May 14, 2012

Conflict of interest: none. 
The dopamine deficiency causes basal ganglia dysfunction, and less cortical excitation. However, dopaminergic neurons are not exclusively related to motor control, but also take part in several other brain functions such as cognition and language. Interestingly, focal lesions affecting the basal ganglia are often followed by behavioral and language disorders, that are in some cases more predominant than the motor symptoms ${ }^{(2)}$.

The PD diagnosis is clinically based on the presence of cardinal symptoms: bradykinesia, rigidity, rest tremor, and postural instability ${ }^{(1)}$. The severity of the disease can be stratified according to routinely used scales as the Unified Parkinson's Disease Rating Scale (UPDRS) and the Hoehn \& Yahr Scale ${ }^{(3,4)}$.

Drug therapy has a vital importance in PD, since it can provide improvement of motor handicap in spite of not being curative. The initiation of antiparkinsonian medication in early PD is followed by a phase of good or excellent response in almost all patients, but in the course of their disease, most of them will developed motor complications. Because the physiopathology of $\mathrm{PD}$ is much more than dopamine deficiency and several other neurotransmitter systems may also play a role in the disease, there are drugs acting either directly in the dopaminergic system or in non-dopaminergic sites $^{(5,6)}$. The main drugs are shown in table 1 , as well as their mechanism of action. Among all drugs used, levodopa is considered the gold-standard since it is the most potent agent that leads to motor improvement, and better quality of life.

Different neuroimaging techniques are now able to show brain functioning during cognitive tasks. It was first possible with SPECT and PET, more invasive techniques due to intravenous infusion of radiotracers, and last with the functional Magnetic Resonance Imaging (fMRI) based on the Blood Oxygenation Level Dependent (BOLD) effect, which can detects differences cerebral oxygenation ${ }^{(7)}$. Generally, a particular task is performed repeatedly inside the MR equipment, while cerebral slices are acquired at each 2 or 3 seconds. Usually each run has 100 to 300 cerebral volumes, at 3 to 10 minutes. The raw data is post-processed for movement and spin history corrections, before the fMRI statistical analysis. Different softwares may provide the areas with MR signal variations compatible with those expected for the task.

In healthy volunteers, the fMRI confirmed the initially described language related areas, as "Broca area" in left middle and inferior frontal gyri related to verbal fluency(8), and "Wernicke area" in left posterior superior temporal gyrus, related to phonological and semantic processing. It also confirmed areas compatible to lesion-based studies, as left middle and inferior temporal, fusiform, and angular gyri (left temporo-parietal language areas outside the traditional "Wernicke area"), extensive left prefrontal language areas outside the classical "Broca area" (9).

Although the beneficial effect of levodopa on PD motor control has been well documented, its effect on speech control is controversial ${ }^{(6,10)}$. Concerning to the hypophonetic dysarthria, the levodopa intake increased loudness and faster the rate of speech, had not influenced the pitch and articulation, but caused severe intensity decay ${ }^{(8)}$. To the lexical-semantic aspect, the PD patients showed a lower average word frequency, in a controlled oral word association test, suggesting increased spreading activation ${ }^{(9)}$.

Table 1. Main antiparkinsonian drugs: category, active principle, Brazilian commercial brand name and mechanism of action

\begin{tabular}{|c|c|c|c|}
\hline Category & Active principle & Brazilian commercial brand name & Mechanism of action \\
\hline Dopamine agonists & Pramipexole & Sifrol ${ }^{\circledR}$ & Striatal dopamine receptor activation \\
\hline Anticholinergic & Biperiden & Akineton $^{\circledast}$, Artane $^{\circledast}$, Parkiso $^{\circledast}$ & $\begin{array}{l}\text { Atropine-like blocking effect on peripheral structures and muscarinic } \\
\text { receptors }\end{array}$ \\
\hline Levodopa & $\begin{array}{l}\text { Carbidopa-levodopa } \\
\text { or benserazide-levodopa }\end{array}$ & Prolopa ${ }^{\circledast}$, Parkidopa ${ }^{\circledast}$, L-dopa $^{\circledast}$, Duodopa ${ }^{\circledast}$ & Direct dopamine precursor \\
\hline Antiglutamatergic & Amantadine & Mantidan ${ }^{\circledR}$ & $\begin{array}{l}\text { Increases dopamine release and weak antagonist of the NMDA type } \\
\text { glutamate receptor }\end{array}$ \\
\hline MAO-I & Selegiline & Deprilan $^{\circledast}$, Selegina ${ }^{\circledast}$ & Selective inhibitor of MAO-B \\
\hline COMT-I & Entacapone & Comtam $^{\circledast}$, Adacapone ${ }^{\circledast}$ & $\begin{array}{l}\text { Prevents COMT from metabolizing L-DOPA into 3-methoxy-4-hydroxy- } \\
\text { L-phenylalanine (3-OMD) in the periphery, when administered in } \\
\text { conjunction with dopaminergic agents such as L-DOPA }\end{array}$ \\
\hline
\end{tabular}


As far as we know, there are no studies in PD showing medication-related differences in brain language areas assessed by fMRI. Hence, in this study we investigated whether PD patients taking or not levodopa would have different brain activation patterns in language areas related to word generation.

We hypothesized that patients taking levodopa had more extensive left frontal and temporo-parietal activation.

\section{OBJECTIVE}

Our aim was to identify the effect of levodopa in brain areas of PD patients during a verbal fluency fMRI task, comparing patients taking and not taking levodopa with healthy volunteers.

\section{METHODS}

\section{Ethics}

It was a prospective non-interventional transversal study, approved by the Research and Ethics Committee from the Hospital Israelita Albert Einstein (HIAE).

All subjects signed the informed consent according to institutional rules, and they did not receive financial reward for the participation.

\section{Subjects}

We evaluated 50 right-handed patients with clinical diagnosis of PD, mild to moderate disease (Hoehn and Yahr stages 2 and 3), 60\% were men and mean age was 54 years (SD 10.4). All participants were recruited at the Hospital Israelita Albert Einstein and at the Universidade Federal de São Paulo (UNIFESP). They were diagnosed with idiopathic PD according to the UK Parkinson's Disease Brain Bank criteria ${ }^{(11)}$.

Patients were classified according to the levodopa intake at the moment of the exam. We excluded patients with 10 or more years of disease duration and severe non-motor symptoms like depression, dementia and psychoses, aiming a homogeneity in the sample. The subgroups profile is shown in table 2.

The control group was matched by age and gender, and consisted of 47 healthy right-handed subjects, $55 \%$ were men and the mean age was 52 years (SD 11.3). Participants were from the same environment (friends, non-consanguineous relatives and neighbors). All subjects underwent clinical and neurological examination.
Table 2. Profile of levodopa and no levodopa subgroups

\begin{tabular}{|c|c|c|}
\hline Groups & Levodopa & No levodopa \\
\hline N & 18 & 7 \\
\hline Gender $\hat{~} 1 / q$ & $10(56 \%) / 8(54 \%)$ & $5(72 \%) / 2(28 \%)$ \\
\hline Age (SD) & $54(11.6)$ & $52(11.5)$ \\
\hline Scholarship & Fundamental & Fundamental \\
\hline Disease time years (SD) & $6(1.9)$ & $5(1.9)$ \\
\hline Hoehn \& Yahr Stage & 2.1 & 2.2 \\
\hline Dopamine equivalent dose* $(\mathrm{mg})$ & 1,333 & 403 \\
\hline
\end{tabular}

\section{Image acquisition features}

All images were acquired using a 3T Magneton Tim Trio MR system (Siemens, Germany), with $45 \mathrm{mT} / \mathrm{m}$ gradient strength, $200 \mathrm{~T} / \mathrm{m} / \mathrm{sec}$ gradients slew rate, and 12 channels head. Structural images were acquired using a volumetric T1 MPRAGE $\left(1 \mathrm{~mm}^{3}\right.$ isotropic voxels). The fMRI data was collected using GRE compressed EPI BOLD, TR 4000ms (2000ms of silent interval for verbal responses), TE $30 \mathrm{~ms}$, FA 90 , and $64 \times 64$ matrix. In total, 126 volumes were collected; each one with 32 ACPC oriented slices, and $3.3 \mathrm{~mm}^{3}$ isotropic voxels. Total task time was 8 hours and 42 minutes.

\section{fMRI task}

The fMRI paradigm to evaluate the expression component of language was a word generation verbal fluency task, according to figure 1. We used an ABC parametric block design task (high demand/low demand/control blocks). Subjects were instructed to say words beginning with the presented letter under semantic restrictions in both high and low demand conditions (repetitions, derivatives, nouns of subjects or places were not allowed). In the high demand condition the same letter was repeated seven times; in the low demand task different letters were presented,

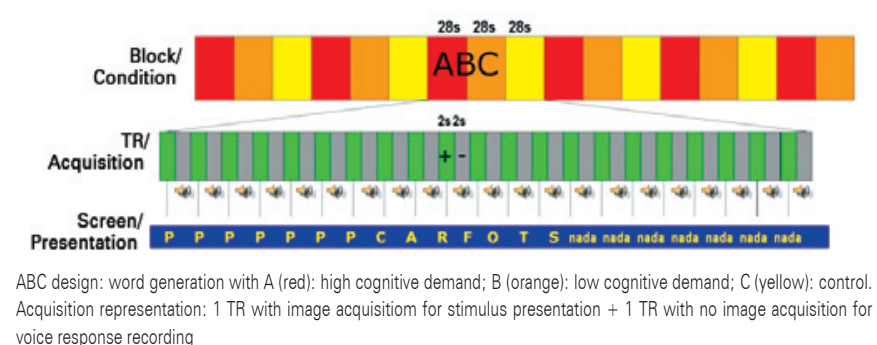

Figure 1. Paradigm scheme 
and in the control block, subjects had to say the Portuguese word nada, which means nothing. All vocal responses were recorded.

It was visually presented with NNL basic fMRI system (NordicNeuroLab Inc, Norway). We used E-Prime (Psychology Software Tools Inc, USA) for task programming and behavior (motor) response recording.

In order to minimize motor artifacts during scanning, subjects were positioned within the scanner gantry with lateral foam pads, and using tightly occlusive earplugs. They were instructed not to move during image acquisitions. All patients were scanned in the "on" state of medication, the best time interval after the drug intake to perform motor abilities, which was previously defined by the neurologist.

\section{fMRI analysis}

We used for fMRI analysis the XBAM software (www. brainmap.co.uk); a package based on non-parametric analysis ${ }^{(12)}$. This analysis approach has been shown to produce better type I error control, and increased sensitivity over most traditional approaches ${ }^{(13)}$. Images were processed using slice time correction, head movement realignment, spatial smoothing $(\mathrm{FWHM}=$ $7.8 \mathrm{~mm})$, and spatial normalization. Individual activation maps were obtained using the general linear model (GLM). The hemodynamic response function was modeled through linear combinations of two Poisson functions with peaks in 4 and 8 seconds after stimuli.

We obtained the brain activation maps evaluating the verbal fluency conditions using a parametric model that searches for areas where BOLD response amplitudes are linearly proportional to the expected responses. For each condition, the residual sumof-squares ratio (SSQr) between the constrained (assuming no activation) and unconstrained model at each voxel was calculated. This measure is proportional to F-statistics in regression models, and quantifies the significance of activation. The SSQr maps in Talairach space were calculated independently for each subject, representing the activation level ${ }^{(12)}$. The maps of differences on activation between the groups were obtained using the analysis of variance (ANOVA). The statistical significance was assessed applying permutation methods ${ }^{(12)}$, and for autocorrelation method, we used a wavelet re-sampling that maintains the noise structure of the data. The type I error was controlled considering differences with uncorrected p-wise cluster values less than 0.01. Regarding the cluster limiarization, we used the mass-cluster algorithm, also implemented to fit to local variations in the time-series behavior.

The resulting images from the statistical maps showed areas more related to task in color scale, yellow higher than red ones.

\section{RESULTS}

The group analysis showed similar brain activated clusters within low and high cognitive demand tasks, as shown in figure 2 and table 3.

The patients using levodopa had more BOLDeffect in the medial frontal areas, including supplementary motor area and middle cingulate gyrus; bilateral frontal gyri, including superior, middle and inferior; left perirolandic areas including pre and post central gyri; bilateral insula and

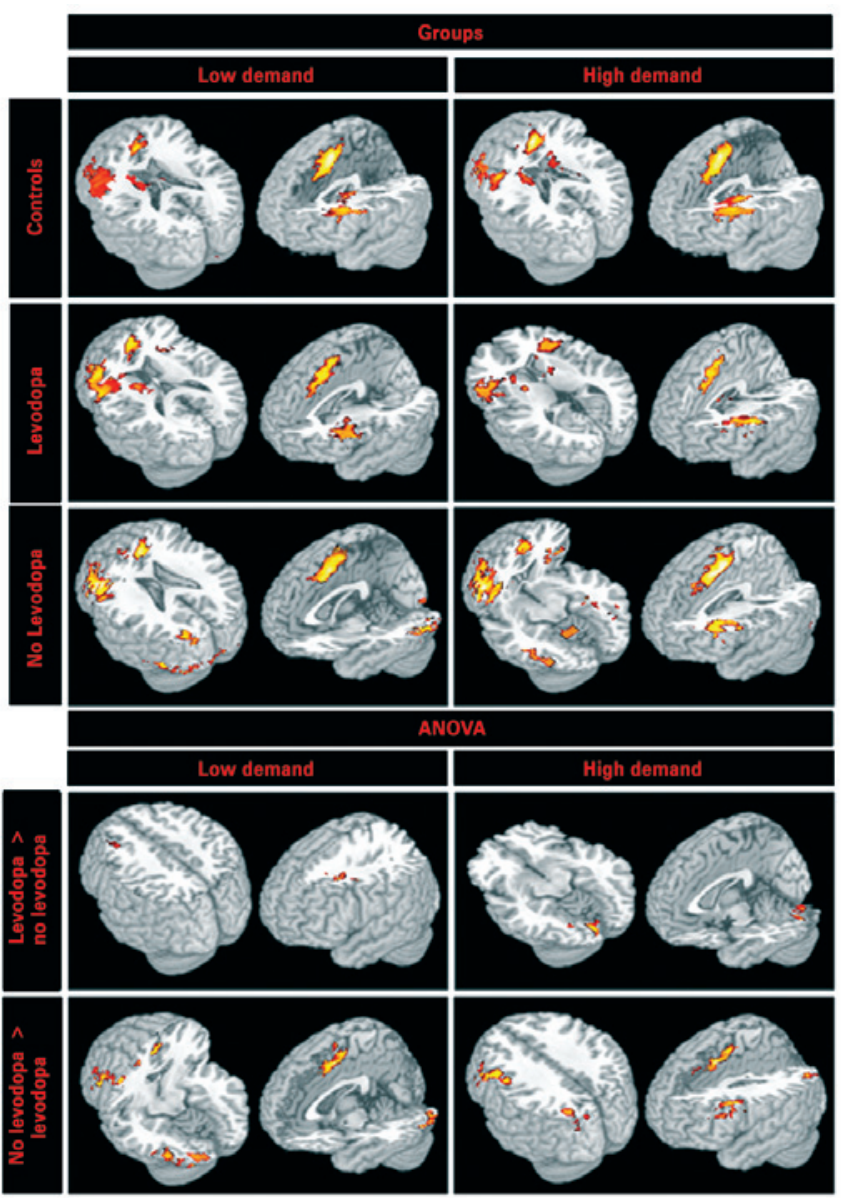

Figure 2. BOLD images for groups (controls, levodopa and non-levodopa patients) and the comparison of them (levodopa $>$ or $<$ than non-levodopa) with $2 \times 2$ ANOVA, $p<0.005$ 
Table 3. Differences in activation areas between groups of Parkinson disease patients during the verbal fluency paradigm

\begin{tabular}{|c|c|c|c|c|c|c|c|c|c|}
\hline & & cide & PAa & & Tournoux co & & Peak & Number & Cluster \\
\hline & Brain region & Side & $\mathbf{B A}^{\mathrm{a}}$ & $x$ & $y$ & $z$ & $\beta$ SSOr ${ }^{c}$ & $\overline{\text { voxels }^{d}}$ & $\overline{p \text {-value }}{ }^{\mathrm{e}}$ \\
\hline & Levodopa & & & & & & & & \\
\hline & Supplementary motor area & $R / L$ & $6,32,8,4$ & $8 /-13 / 2 /-10$ & $13 / 21 / 25 /-17$ & $52 / 59$ & 16.02 & 258 & 0.001167 \\
\hline & Superior frontal gyrus & $R / L$ & 8 & $2 /-25$ & $31 / 5$ & $59 / 52$ & & & \\
\hline & Middle frontal gyrus & L & $46,44,9,6$ & $-28 /-41$ & $52 / 21$ & $33 / 52$ & & & \\
\hline & Postcentral gyrus & L & $43,3,4$ & -60 & -8 & 33 & & & \\
\hline & Angular gyrus & L & 48,39 & -46 & -41 & 33 & & & \\
\hline & Insula & $R / L$ & 48,47 & $30 /-33$ & $14 / 26$ & $17 / 3$ & & & \\
\hline & Middle occipital gyrus & R & 37,19 & 37 & -68 & 3 & & & \\
\hline & Inferior temporal gyrus & $\mathrm{R}$ & 37 & 56 & -60 & -14 & & & \\
\hline & Lingual gyrus & R & 19,18 & 30 & -86 & -14 & & & \\
\hline 这 & Cerebelum & R & 37 & 27 & -54 & -30 & & & \\
\hline 茨 & No levodopa & & & & & & & & \\
\hline ( & Supplementary motor area & $R / L$ & $32,6,8$ & $20 /-7 / 20$ & $45 / 54 /$ & $52 / 58$ & & & \\
\hline & Superior frontal gyrus & $\mathrm{L}$ & $6,8,32$ & $-26 /-7 /-9$ & $-4 / 31 / 23$ & $61 / 45$ & & & \\
\hline & Middle frontal gyrus & $\mathrm{L}$ & $45,46,9,6$ & $-46 /-35 /-44 /-29$ & $45 / 46 / 27 /-3$ & $7 / 33 / 45 / 54$ & & & \\
\hline & Inferior frontal gyrus & $\mathrm{L}$ & 45,48 & $-53 /-52$ & $37 / 20$ & $-3 / 24$ & & & \\
\hline & Precentral gyrus & $L$ & 44,6 & $-48 /-39$ & $5 /-12$ & $33 / 61$ & 14.53 & 294 & 0.001266 \\
\hline & Postcentral gyrus & L & 4 & -55 & -15 & 45 & & & \\
\hline & Insula & $R / L$ & 48,49 & $33 /-38$ & $31 / 26$ & $7 /-3$ & & & \\
\hline$\ddot{q}$ & Middle cingulate gyrus & $R / L$ & 24,32 & $2 /-9$ & $-2 / 14$ & 45 & & & \\
\hline$\sum_{0}^{\frac{1}{2}}$ & Inferior temporal gyrus & $\mathrm{L}$ & 37,20 & $-51 /-49$ & $-57 /-49$ & 13 & & & \\
\hline & Levodopa & & & & & & & & \\
\hline & Supplementary motor area & $R / L$ & $6,32,8$ & $10 /-8 /-5$ & $7 / 9 / 22$ & $7 / 9$ & 2042 & 20? & 0001200 \\
\hline & Superior frontal gyrus & $R / L$ & $32,8,6$ & $10 /-6 /-23$ & $27 / 34 /-7$ & $36 / 43 / 62$ & 20.42 & 322 & 0.001280 \\
\hline & Middle frontal gyrus & $R / L$ & $46,45,9,6$ & $37 /-45 /-46 /-36$ & $47 / 34 / 21 / 1$ & $24 / 33 / 43 / 62$ & & & \\
\hline & Inferior frontal gyrus & $R / L$ & $48,45,44$ & $36 /-56 /-49$ & $26 / 13 / 20$ & $17 / 24 / 36$ & & & \\
\hline & Precentral gyrus & $R / L$ & $6,44,4$ & $60 /-54 /-46$ & $8 / 9 /-9$ & $24 / 36 / 43$ & & & \\
\hline & Postcentral gyrus & $\mathrm{L}$ & $6,48,4,3$ & -57 & -2 & 36 & & & \\
\hline & Supramarginal & $L$ & 2 & -56 & -26 & 36 & & & \\
\hline$\leq$ & Rolandic opercular & L & 48 & -55 & 14 & 24 & & & \\
\hline Lب & Middle cingulate gyrus & $R / L$ & 24,32 & $-7 / 8$ & $8 / 15$ & 43 & & & \\
\hline $\bar{c}$ & Insula & $R / L$ & 48 & $36 /-39$ & $23 / 11$ & 7 & 3791 & 855 & 001280 \\
\hline & Putamen & $R / L$ & 48 & $21 /-25$ & $17 / 12$ & 7 & 37.91 & 855 & 0.001280 \\
\hline & Inferior temporal gyrus & $\mathrm{R}$ & 37 & 52 & -56 & -8 & & & \\
\hline & Inferior occipital gyrus & R & 18,37 & 49 & -62 & -15 & & & \\
\hline & Hippocampus & R & 37 & 32 & -33 & -5 & & & \\
\hline & Thalamus & R & * & 7 & 7 & 16 & & & \\
\hline & Caudate nuclei & $R / L$ & 25,48 & $16-23$ & $19 / 21$ & 7 & & & \\
\hline & Fusiform gyrus & $\mathrm{R}$ & 19,37 & 36 & -62 & -8 & & & \\
\hline & Lingual gyrus & R & 18 & 29 & -88 & -15 & & & \\
\hline
\end{tabular}

${ }^{a}$ Numbers referent to approximate Broadmann areas (BA); ${ }^{b}$ coordinates of the voxel of maximal statistical significance within each region, according to the atlas of Talairach and Tornoux; ${ }^{c}$ peak of $\beta$ sum-of-squares ratio (SSQr) for the voxel of maximal statistical significance in each region; ${ }^{d}$ total number of contiguous voxels in each region that had statistical significance $(p<0.005) ;{ }^{e}$ level of statistical significance for each voxel cluster.

BA: Broadmann areas; ANOVA: analysis of variance; R: right; L: left. 
...continuation

Table 3. Differences in activation areas between groups of Parkinson disease patients during the verbal fluency paradigm

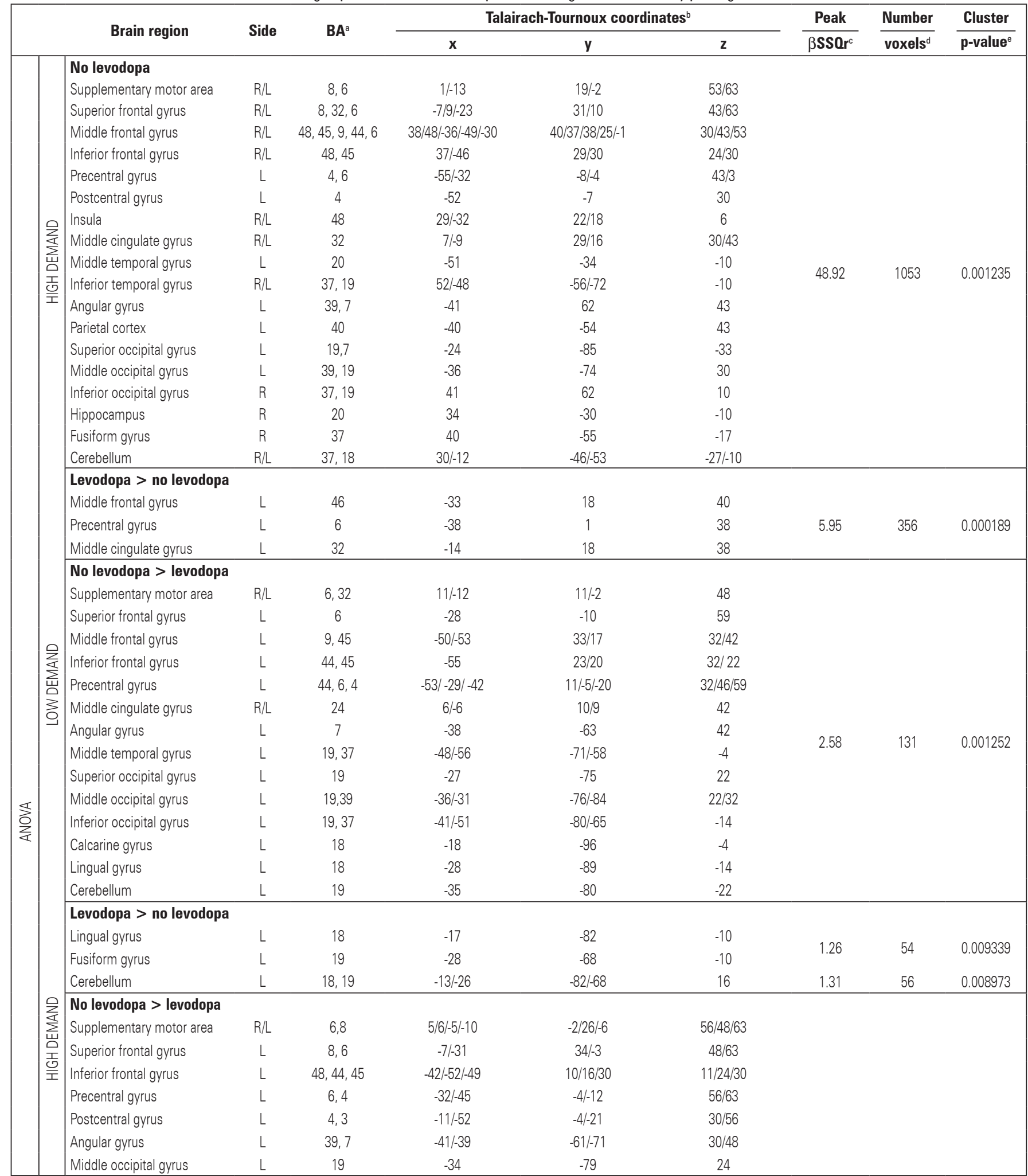

${ }^{a}$ Numbers referent to approximate Broadmann areas (BA); ${ }^{b}$ coordinates of the voxel of maximal statistical significance within each region, according to the atlas of Talairach and Tornoux; ${ }^{\circ}$ peak of $\beta$ sum-of-squares ratio (SSOr) for the voxel of maximal statistical significance in each region; ${ }^{d}$ total number of contiguous voxels in each region that had statistical significance $(p<0.005)$; ${ }^{*}$ level of statistical significance for each voxel cluster

BA: Broadmann areas; ANOVA: analysis of variance; R: right; L: left.

striatum; thalamus; left parietal; right temporooccipital areas; and right cerebellum.
The patients without levodopa had more BOLDeffect in bilateral medial frontal areas; left frontal 
gyri; left perirolandic areas; bilateral insula; left temporo-parietal areas, bilateral occipital areas; and right cerebellum.

Direct contrast (ANOVA) between with and without levodopa intake groups showed similar pattern for low and high cognitive demand tasks, only for the areas activated more in the group without levodopa, as seen in figure 2 and table 3.

Patients without levodopa had more brain activated clusters than those using levodopa in the medial frontal areas; left frontal gyri; left parietooccipital areas; and left cerebellum. Non-levodopa patients also had more BOLD-effect in left temporal areas for low demand task, and perirolandic areas for high demand task. Levodopa patients had more BOLD-effect than non-levodopa ones in few areas: for low demand task it was seen in the left frontal white matter, and for the high demand task in the left cerebellum.

The healthy volunteers' group had more BOLD effect in the left frontal gyri extending to left striatum and to medial frontal areas, and right inferior temporooccipital areas extending to cerebellum, as showed in figure 2 .

\section{DISCUSSION}

According to our data the brain circuitry involved in the verbal fluency for word generation is slightly different in patients who used levodopa or not used it. When levodopa was not used, more cortical neurons were recruited to perform the task, especially in the left hemisphere. These left fronto-parietal areas were presented in both groups, but the direct contrast showed that their BOLD effect was more intense and extended in the no levodopa group. These areas can be named as related to language, since they were also activated in the healthy volunteers during verbal fluency paradigms, not only in our study but also in other populations ${ }^{(8,9)}$. The more intense and extended activation in left language areas in no levodopa group can indicate that when there is no more response to dopamine, the brain has to make some adaptative changes to perform the same effort, which in this case, for language, it recruited neighbors areas. Our results are in the same direction than the previous one working with memory tasks ${ }^{(14)}$. Studying patients before and after the levodopa intake, more activation during the hypodopaminergic state was observed, inferring that mesocortical dopaminergic system facilitates working memory function via direct inputs to prefrontal cortex.
We found the parieto-occipital area less active in the levodopa group than in the no levodopa one. In the same direction, studying motor sequence learning with PET, Feigin et al. correlated an impaired performance to defective activation of cortical association pathways, most notable in the parietooccipital region, after levodopa intake in responsive PD patients ${ }^{(15)}$. The presence of more BOLD effect in these areas may also represent the adaptative changes. Probably, in the no levodopa patients, visual areas are recruited to perform the same task.

Considering the group maps, the striatal activation detected in the healthy volunteers was only seen in the PD patients taking levodopa. So, we believe that the striatal activation in levodopa patients is similar to the "normal" activity pattern. Levodopa had been shown to "normalize" activation in motor areas, after the dose intake in PD patients responsive to it ${ }^{(16,17)}$.

To our knowledge, this is the first report comparing cerebral areas in PD patients taking or not taking levodopa. We have chosen this approach to access the cerebral activity adaptation to the environment when the complex levodopa/dopamine receptors are working and when it is not. The majority of studies regarding drug modulation are focused in the acute/ sub-acute effects of levodopa in a circuitry responsive to it. They usually test the same patients performing tasks in the withdrawal (off) and after the intake (on) of levodopa ${ }^{(14-19)}$. Unfortunately, there is no ideal model to study cerebral language circuitry differences induced by drugs.

Our data must be interpreted considering the possible interaction effect between drugs, not quantifiable, nor even identifiable. To reduce this bias, we opted to exclude a quarter of the sample, already scanned, to guarantee groups with homogenous PD stratification. We calculated the dopamine equivalent doses, as recommended in the literature, but as the formula includes the IMAO, the value of the no levodopa patient was not nule. It is also remarkable the fact that amantadine is not considered in the dopamine equivalent dose formula ${ }^{(20)}$. Although it enhances the release of stored catecholamines (dopamine) from intact dopaminergic terminals and inhibits catecholamine reuptake at the presynaptic terminal.

Levodopa effect had also been studied in healthy volunteers, associating it to a decreased activation in amigdala $^{(21)}$, anterior cingulate, and dorsal prefrontal cortex $^{(22)}$. However, the results are not comparable 
to our objectives, since PD patients have specific cerebral impairment due to the dopamine deficit, and levodopa does not have the same effect in normal and in impaired circuitries.

We focused in levodopa action in language because of the uncertainty its improvement in cognitive function ${ }^{(6)}$. The proven benefits are related to the vocalization, improving in the variability, pitch and loudness ${ }^{(10)}$. The paradigm chosen, word generation, had the highest inter and intra-individual reproducibility, according to Harrington et al.(23). To guarantee the compliance to the task a compressed EPI sequence was used with multiple pauses, so the overt responses could be checked in the equipment silent interval.

In both groups the comparison of different cognitive demand degrees resulted in not so many different brain areas. Only the ANOVA showed different areas more active in levodopa group than in no levodopa group for low and high demand, but none of them were remarkable.

If the pattern is more similar to the no levodopa group, the neurologist may consider skip the levodopa dose optimization tries, replacing it directly to other drugs. This makes the fMRI a tool with another clinical application in PD.

\section{CONCLUSIONS}

PD patients without levodopa replacement, during a verbal fluency effort, had more diffuse and intense cerebral activated voxels in left hemisphere than patients taking levodopa. This was mainly characterized in the frontal and parieto-occipital areas, representing not only typical language areas, but also additional recruited circuitries, as visual.

During verbal fluency, the striatal BOLD effect of the patients with levodopa intake was similar to the one from healthy volunteers.

Although more studies are needed in this field, these are initial evidences of levodopa role to inhibit the activation in parieto-occipital compensating areas, as they have less activated voxels in the levodopa group than in the no levodopa one.

\section{ACKNOWLEDGMENTS}

This study was supported by Fondation Philanthropique Edmond J. Safra grant.

We thank the staff of the Instituto do Cérebro and the Departamento de Imagem of the Hospital Israelita Albert Einstein, for the kind assistance.

\section{REFERENCES}

1. Davie CA. A review of Parkinson's disease. Br Med Bull. 2008;86(1):109-27.

2. Frederico WS, Oga S, Pequeno ML, Taniguchi SF. Efeitos extrapiramidais como consequência de tratamento com neurolépticos. Einstein (São Paulo). 2006;6(1):51-5.

3. Movement Disorder Society Task Force on Rating Scales for Parkinson's Disease. The Unified Parkinson's Disease Rating Scale (UPDRS): status and recommendations. Mov Disord. 2003;18(7):738-50.

4. Hoehn MM, Yahr MD. Parkinsonism: onset, progression, and mortality Neurology. 1967;17(5):427-42.

5. Ferraz HB, Borges V. Como diagnosticar e tratar doença de Parkinson. Rev Bras Med. 2002;59(4):207-19.

6. Ho AK, Bradshaw JL, Lansek R. For better or worse: The effect of levodopa on speech in Parkinsons disease. Mov Disord. 2008;23(4):574-80.

7. Ogawa S, Lee TM, Nayak AS, Glynn P. Oxygenation-sensitive contrast in magnetic resonance image of rodent brain at high magnetic fields. Magn Reson Med.1990;14(1):68-78.

8. Brannen JH, Badie B, Moritz CH, Quigley M, Meyerand ME, Haughton VM. Reliability of functional MR imaging with word-generation tasks for mapping Broca's area. AJNR Am J Neuroradiol. 2001;22(9):1711-8.

9. Binder JR, Frost JA, Hammeke TA, Cox RW, Rao SM, Prieto T. Human brain language areas identified by functional magnetic resonance imaging. $J$ Neurosci. 1997;17(1):353-62.

10. De Letter M, Santens P, Estercam I, Van Maele G, Bodt M, Boon P, et al. Levodopa-induced modifications of prosody and comprehensibility in advanced Parkinson's disease as perceived by professional listeners. Clin Linguist Phon. 2007;21(10):783-91.

11. Hughes AJ, Daniel SE, Kilford L, Lees AJ. Accuracy of clinical diagnosis of idiopathic Parkinson's disease: a clinico-pathological study of 100 cases. J Neurol Neurosurg Psychiatry. 1992;55(3):181-4.

12. Brammer MJ, Bullmore ET, Simmons A, Williams SC, Grasby PM, Howard $\mathrm{RJ}$, et al. Generic brain activation mapping in functional magnetic resonance imaging: a nonparametric approach. Magn Reson Imaging. 1997;15(7): 763-70.

13. Bullmore E, Long C, Suckling J, Fadili J, Calvert G, Zelaya F, et al. Colored noise and computational inference in neurophysiological (fMRI) time series analysis: resampling methods in time and wavelet domains. Hum Brain Mapp. 2001;12(2):61-78

14. Mattay VS, Tessitore A, Callicott JH, Bertolino A, Goldberg TE, Chase TN, et al. Dopaminergic modulation of cortical function in patients with Parkinson's disease. Ann Neurol. 2002;51 (2):156-64.

15. Feigin A, Ghilardi MF, Carbon M, Edwards C, Fukuda M, Dhawan V, et al. Effects of levodopa on motor sequence learning in Parkinson's disease. Neurology. 2003;60(11):1744-9.

16. Buhmann C, Glauche V, Stürenburg HJ, Oechsner M, Weiller C, Buchel C. Pharmacologically modulated fMRI- cortical responsiveness to levodopa in drug naive hemiparkinsonian patients. Brain. 2003;126(Pt 2):451-61.

17. Haslinger B, Erhard P, Kämpfe N, Boecker H, Rummeny E, Schwaiger M, et al. Event-related functional magnetic resonance imaging in Parkinson's disease before and after levodopa. Brain. 2001;124(Pt 3):558-70.

18. Yang $\mathrm{Cl}$, Yang ML, Huang JC, Wan YL, Jui-Fang Tsai R, Wai YY, et al. Functional MRI of amblyopia before and after levodopa. Neurosci Lett. 2003;339(1): 49-52.

19. Cools R, Lewis SJ, Clark L, Barker RA, Robbins TW. I-DOPA disrupts activity in the nucleus accumbens during reversal learning in Parkinson's disease. Neuropsychopharmacology. 2007;32(1):180-9. 
20. Tomlinson CL, Stowe R, Patel S, Rick C, Gray R, Clarke CE. Systematic review of levodopa dose equivalency reporting in Parkinson's disease. Mov Disord. 2010;25(15):2649-53.

21. Delaveau P, Salgado-Pineda P, Wicker B, Micallef-Roll J, Blin Ol. Effect of levodopa on healthy volunteers' facial emotion perception: an fMRI study. Clin Neuropharmacol. 2005;28(6):255-61.
22. Copland DA, McMahon KL, Silburn PA, de Zubicaray Gl. Dopaminergic neuromodulation of semantic processing: A 4-T fMRI study with levodopa. Cereb Cortex. 2009;19(11):2651-8.

23. Harrington GS, Buonocore MH, Farias ST. Intrasubject reproducibility of functional MR imaging activation in language tasks. AJNR Am J Neuroradiol. 2006;27(4):938-44. 